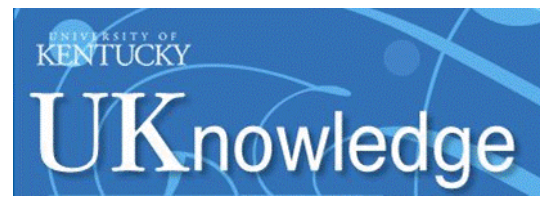

University of Kentucky

UKnowledge

Biosystems and Agricultural Engineering Faculty Publications

\title{
Automated Calibration of Electrochemical Oxygen Sensors for Use in Compost Bedded Pack Barns
}

\author{
John T. Evans \\ University of Kentucky, john.evans@uky.edu \\ Michael P. Sama \\ University of Kentucky, michael.sama@uky.edu \\ Joseph L. Taraba \\ University of Kentucky, joseph.taraba@uky.edu \\ George B. Day \\ University of Kentucky, george.day@uky.edu
}

Follow this and additional works at: https://uknowledge.uky.edu/bae_facpub

Part of the Bioresource and Agricultural Engineering Commons, and the Environmental Sciences Commons

Right click to open a feedback form in a new tab to let us know how this document benefits you.

\section{Repository Citation}

Evans, John T.; Sama, Michael P.; Taraba, Joseph L.; and Day, George B., "Automated Calibration of Electrochemical Oxygen Sensors for Use in Compost Bedded Pack Barns" (2017). Biosystems and Agricultural Engineering Faculty Publications. 136.

https://uknowledge.uky.edu/bae_facpub/136

This Article is brought to you for free and open access by the Biosystems and Agricultural Engineering at UKnowledge. It has been accepted for inclusion in Biosystems and Agricultural Engineering Faculty Publications by an authorized administrator of UKnowledge. For more information, please contact UKnowledge@lsv.uky.edu. 


\section{Automated Calibration of Electrochemical Oxygen Sensors for Use in Compost Bedded Pack Barns}

Digital Object Identifier (DOI)

https://doi.org/10.13031/trans.12099

Notes/Citation Information

Published in Transactions of the ASABE, v. 60, issue 3, p. 957-962.

(C) 2017 American Society of Agricultural and Biological Engineers

The copyright holder has granted the permission for posting the article here.

This article is available at UKnowledge: https://uknowledge.uky.edu/bae_facpub/136 


\title{
TECHNICAL NOTE:
}

\section{AUTOMATED CALIBRATION OF ELECTROCHEMICAL OXYGEN SENSORS FOR USE IN COMPOST BEDDED PACK BARNS}

\author{
J. T. Evans, M. P. Sama, J. L. Taraba, G. B. Day
}

\begin{abstract}
The objective of this study was to develop an automated calibration process for a galvanic cell type oxygen sensor. The manufacturer recommended a two-point calibration at room temperature; however, testing revealed that the response was not linear when both the temperature and oxygen concentrations varied. Thus, additional points were needed to generate a representative calibration equation and to reduce the sensor prediction interval. The calibration process needed to be capable of automatically recording sensor response (voltage) at an array of temperatures and oxygen concentrations. Calibration gases were used to precisely control the oxygen concentration inside a small manifold, and an electronically controlled water bath was used to regulate the sensor and gas temperature. A custom computer program controlled the sampling order and the data collection process. The responses for three sensors were recorded at six temperature $\left(10^{\circ} \mathrm{C}, 20^{\circ} \mathrm{C}, 30^{\circ} \mathrm{C}, 40^{\circ} \mathrm{C}, 50^{\circ} \mathrm{C}\right.$, and $\left.60^{\circ} \mathrm{C}\right)$ and five oxygen concentration $\left(0 \%, 5 \%, 10 \%, 15 \%\right.$, and $20 \% \mathrm{O}_{2}$ absolute) combinations, for a total of 30 measurements per calibration. Calibration data were used to create a second-degree polynomial model with oxygen sensor voltage and temperature as input parameters, which reduced the prediction interval by over $1 \% \mathrm{O}_{2}$ for each of the three sensors tested. The resulting prediction intervals ranged between $0.75 \%$ and $0.95 \% \mathrm{O}_{2}$. Three sensors were mounted in a prototype oxygen probe and tested under controlled conditions to demonstrate the ability to measure oxygen concentration versus depth in a composting environment.
\end{abstract}

Keywords. Aeration, Calibration, Compost, Dairy, Housing, Oxygen.

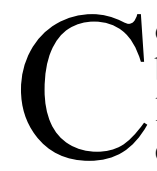

ompost bedded pack (CBP) barns were developed by dairy farmers to improve cow comfort, reduce lameness, and increase cow longevity. CBP barns comprised only $3.2 \%$ of all operations in the U.S. as of 2006 (USDA, 2007). However, the number of CBP barns in Kentucky has risen three-fold from 30 in 2008 to over 90 in 2016. CBP barns are a variation of conventional pack barns that incorporate composting to control moisture and improve cow cleanliness. Proper compost management is paramount to the success of the system. Lack of active composting results in higher bedding moisture and less reduction in volume of animal waste, which decreases animal welfare and reduces the interval between cleanouts, respectively. Further, higher maintained moisture generally increases the amount of bedding material required, which translates to higher cost of operation.

Available oxygen in a compost system has a direct effect

Submitted for review in September 2016 as manuscript number PAFS 12099; approved for publication as a Technical Note by the Plant, Animal, \& Facility Systems Community of ASABE in March 2017.

The authors are John T. Evans, ASABE Member, Graduate Research Assistant, Michael P. Sama, ASABE Member, Assistant Professor, Joseph L. Taraba, ASABE Member, Extension Professor, and George B. Day, ASABE Member, Agriculture Research Specialist, Department of Biosystems Engineering, University of Kentucky, Lexington, Kentucky. Corresponding author: Michael P. Sama, 119 C.E. Barnhart Building, University of Kentucky, Lexington, KY 40546-0276; phone: 859-2184325; e-mail: michael.sama@uky.edu. on the metabolic rate of the aerobic bacteria present. Anaerobic conditions may result when bacteria consume the oxygen from a non-aerated compost system. Anaerobic systems metabolize organic matter more slowly than aerobic systems and produce undesirable compounds such as methane, organic acids, and hydrogen sulfide (Rynk et al., 1992). It is generally accepted that the composting process is working well when the system has the right combination of organic materials, moisture, and oxygen and is producing enough heat to support thermophilic microorganisms. Temperature has been the most common metric used to assess how the system is working. However, temperature is a lagging indicator affected by the moisture content (Agnew and Leonard, 2003) owing to the time required to generate heat at the microbial level. The main disadvantage of using temperature as the primary system indicator is that it is not an instantaneous measure of the state of the compost. Therefore, temperature may not be suitable for assessing rapid changes in the CBP due to tillage or aeration. Instantaneous feedback is desirable when developing best management practices for providing necessary levels of individual ingredients, including oxygen.

Traditional compost management is a well-defined and extensively researched process (Bernal et al., 2009). However, using compost as bedding for animals requires different management techniques. Constant compaction and addition of moisture from the animals requires intensive management incorporating mechanical mixing and aeration. Best management practices are still being established, given the 
relatively small number of barns presently in operation. Producers currently use a variety of soil tillage tools to improve aeration and incorporation of bedding materials. However, no readily available technology exists to quantify the level of aeration in a CBP nor the effects that different tillage methods may have on oxygen levels. Batch methods used for controlling aeration and sampling gases, such as those presented by He et al. (2000), Gea et al. (2004), and Guo et al. (2012), are not suitable for in situ assessment. Particle size and porosity are two other possible parameters that could be used to assess tillage performance, but they are more difficult to measure than free oxygen using off-the-shelf components.

A commercially available soil oxygen sensor (SO-120, Apogee Instruments, Logan, Utah) was chosen to quantify the effects that various tillage methods had on oxygen levels in a CBP. The Apogee sensor was chosen because the broad operating range $\left(-20^{\circ} \mathrm{C}\right.$ to $\left.60^{\circ} \mathrm{C}\right)$ included the recommended operating range for a $\mathrm{CBP}\left(45^{\circ} \mathrm{C}\right.$ to $\left.55^{\circ} \mathrm{C}\right)$ proposed by Black et al. (2013). Manufacturer recommendations outlined a two-point calibration with points taken at ambient air $\left(20.95 \% \mathrm{O}_{2}\right)$ and a zero reading. A temperature correction was applied using a manufacturer-supplied empirical equation; however, initial testing showed that this method resulted in higher than desired prediction intervals (PI) (approx. $\pm 2 \% \mathrm{O}_{2}$ or $20,000 \mathrm{ppm}$ absolute), particularly at the higher temperatures expected in a composting environment. Oxygen levels in a CBP can vary by nearly $21 \% \mathrm{O}_{2}$ absolute between fully anaerobic and fully aerobic conditions. A PI of less than $\pm 1 \% \mathrm{O}_{2}$ (10,000 ppm absolute) was selected for comparing oxygen concentrations in a CBP because it would allow more sensitive detection of statistically significant differences in tillage treatments. However, manual calibration of a single oxygen sensor at five known concentrations and six temperatures required up to $18 \mathrm{~h}$ per sensor, largely because of the time necessary for the gas temperature control system to reach equilibrium. This represented a bottleneck for deploying multiple oxygen sensors at varying spatial locations throughout a CBP.

\section{OBJECTIVES}

The overall objective of this study was to automate the process of calibrating oxygen sensors for use in a composting environment. Specific goals were as follows:

1. Develop an automated method for calibrating multiple oxygen sensors across a range of oxygen concentrations and temperatures.

2. Determine if increasing the number of calibration points and choosing an alternative calibration model would improve the prediction interval to less than $\pm 1 \%$ $\mathrm{O}_{2}$.

3. Demonstrate the use of multiple oxygen sensors for measuring the vertical oxygen profile in compost from a CBP barn.

\section{Materials ANd Methods}

Calibration HaRdWARE

The SO-120 oxygen sensor uses a galvanic cell to produce an electric current, proportional to the oxygen concentration, that is converted internally to a small voltage signal. The sensor output in ambient air conditions $\left(20.95 \% \mathrm{O}_{2}\right)$ is approximately $50 \mathrm{mV}$, or $2.4 \mathrm{mV}$ per $1 \% \mathrm{O}_{2}$. The oxygen sensor is also temperature dependent and includes an internal type-K thermocouple. The thermocouple output is nominally $0.798 \mathrm{mV}$ at $20^{\circ} \mathrm{C}$ and changes linearly by $0.397 \mathrm{mV}$ per $10^{\circ} \mathrm{C}$. A USB data acquisition (DAQ) board (USB-2416, Measurement Computing Corp., Norton, Mass.) was used to convert the voltages to digital signals that could be processed by a computer. This model DAQ includes the ability to directly apply cold-junction compensation and the nominal calibration equation for a type-K thermocouple, so temperature was reported directly in degrees Celsius. The signals were then processed by a Visual Basic program (Microsoft Visual Studio 2012, Microsoft Corp., Redmond, Wash.) that recorded raw voltages from the oxygen sensors, sensor temperatures, and a time stamp. All data were recorded in $1 \mathrm{~s}$ intervals. The program also recorded temperatures from additional type-K thermocouples (PR-K-24-100, Omega Engineering, Stamford, Conn.) used in the experiment for quantifying temperature of the gas external to the oxygen sensor. Data were written to a comma-separated value (CSV) text file that could be directly opened in Microsoft Excel (Microsoft Corp., Redmond, Wash.) for further analysis.

The oxygen sensors were initially placed in a convection drying oven (model 31628, Precision Scientific, Chicago, Ill.) along with a heat exchanger to control the temperature of the gas and the sensor body during calibration. Early experiments showed that the oven was unable to maintain a constant and repeatable temperature because of heater cycling. Therefore, the heat exchanger was moved to a water bath (E300, Lauda-Brinkmann, LP, Delran, N.J.). The water bath featured an RS-232 port, which allowed the temperature control process to be externally automated. The initial oxygen sensor location was outside the bath, with air pumped though a PVC manifold. Thermocouples were used to measure the water bath temperature and gas temperature immediately below each oxygen sensor as it passed through the manifold. The oxygen sensors were equipped with a $12 \mathrm{~V}$ internal heater that was designed to prevent condensation. However, at higher temperature gradients, condensation still formed on the Teflon membrane when warm saturated air was exposed to the cooler sensors, consequently reducing diffusion of oxygen into the sensor. This caused the sensors to malfunction, as exhibited by a loss of voltage signal, or an apparent $0 \% \mathrm{O}_{2}$ measurement. Subsequently, a temperaturecontrolled manifold was developed to better represent the intended operating environment and to reduce the opportunity for condensation to form. The manifold was machined from aluminum and partially submerged in the water bath to better conduct the water bath temperature to the oxygen sensor. Condensation represented a potential problem for field deployment; however, subsequent testing did not result in condensation forming on the sensor membrane during laboratory testing and field use in compost. 


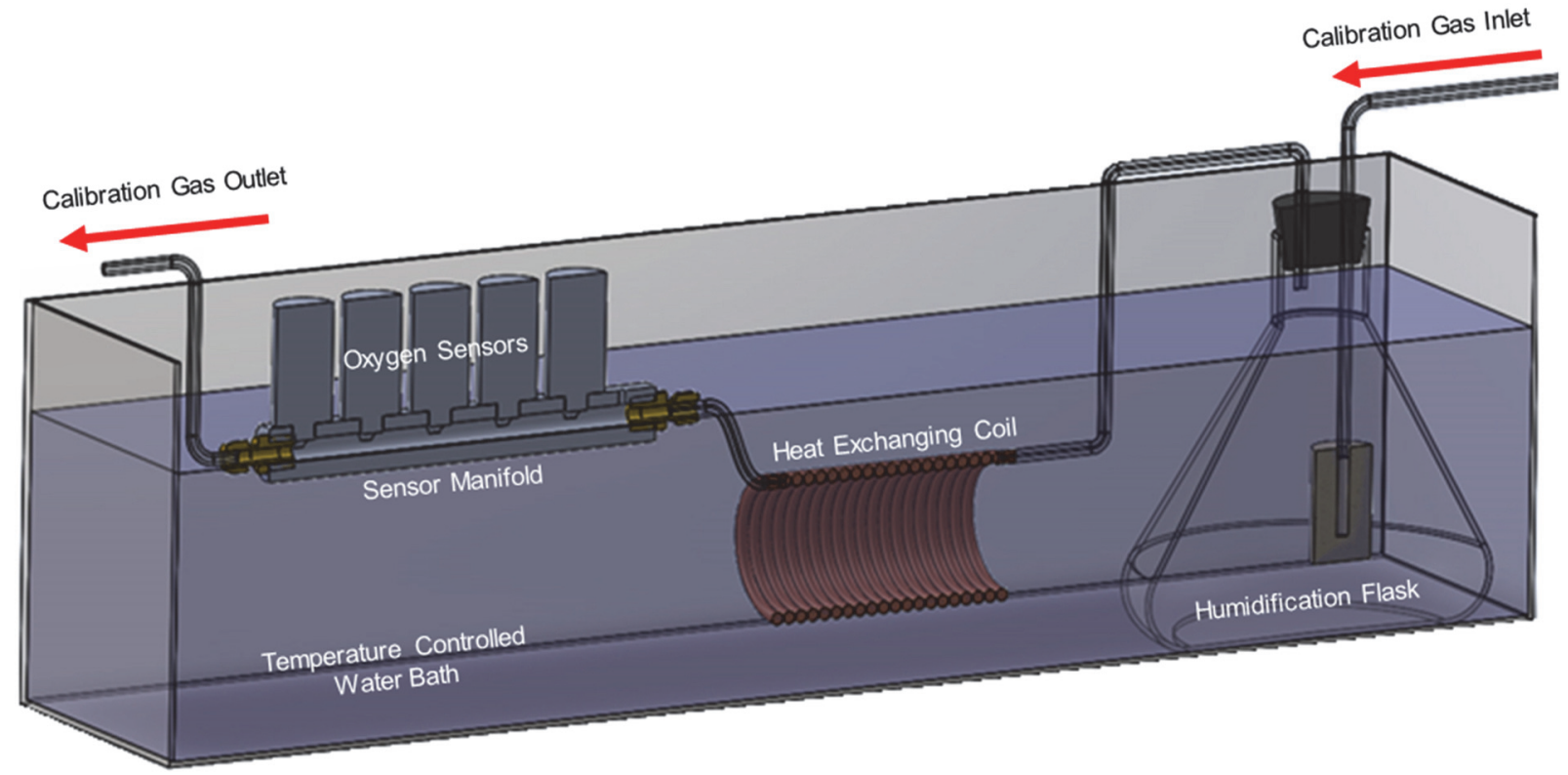

Figure 1. Cutaway diagram of oxygen sensor calibration setup for controlling temperature and adding moisture to calibration gases.

Figure 1 shows the final calibration setup, which consisted of the water bath, humidification flask, heat exchanger coils, and sensor manifold. The entire water bath was covered with foam insulation (not shown) to limit heat transfer to the ambient air and to prevent condensation on the oxygen sensor membrane during calibration.

Solid-state relay switches (ODC5, Opto 22, Temecula, Cal.) and solenoid-operated valves (W26UT, Burkert Contromatic Corp., Irvine, Cal.) were added to control the flow of calibration gases using the DAQ board's digital outputs. Each of the calibration gas cylinders had a pressure/flow regulator (3153351-01-M1L, CONCOA North America, Virginia Beach, Va.) used to set the flow rate of the gas though the system at $2 \mathrm{~L} \mathrm{~min}^{-1}$, which corresponded with the lowest possible pressure setting. A flowmeter (VFA-24, Dwyer Instruments, Michigan City, Ind.) was used to measure the calibration gas flow rate. Calibration gas was initially at ambient air temperature $\left(21^{\circ} \mathrm{C}\right)$ before entering the water bath. The air in the compost was assumed to be saturated (Hogan et al., 1989), so the calibration gas was forced through a diffusion stone and bubbled inside a sealed flask of water submerged in the water bath in an attempt to raise the relative humidity. This simple method may not have resulted in moisture-saturated calibration gas, particularly in instances when the temperature of the gas continued to increase after leaving the humidification flask, but it was deemed sufficient for initial testing.

\section{Calibration Software}

The initial program developed to record data was modified to control the calibration process. The sensors were calibrated using certified mixture calibration gases (NIST, $\pm 2 \%$ accuracy) at five different oxygen concentrations, $0 \% \mathrm{O}_{2}\left(4 \% \mathrm{CO}_{2}\right.$, balance $\mathrm{N}_{2}$ ), $5 \%, 10 \%, 15 \%$, and $20 \% \mathrm{O}_{2}$ (balance $\mathrm{N}_{2}$ ), and six different temperatures $\left(10^{\circ} \mathrm{C}, 20^{\circ} \mathrm{C}, 30^{\circ} \mathrm{C}, 40^{\circ} \mathrm{C}, 50^{\circ} \mathrm{C}\right.$, and $60^{\circ} \mathrm{C}$ ). Discrete gas concentrations were used for this experiment to eliminate the need for a mass flow con-troller and diluter to generate varying oxygen concentrations. The range of temperatures was chosen based on previous observations in a CBP, with the recognition that composting will not likely occur at the lower temperatures selected, to ensure that the sensor calibration encompassed all possible environmental conditions. The program allowed the user to randomize the sampling order, handled the connections to the water bath and the DAQ board, and displayed the raw oxygen sensor voltage, temperature, DAQ error messages (if necessary), and the calibrated percentage of $\mathrm{O}_{2}$ (if a previous calibration had been completed) for each sensor.

Given the relatively long time required to adjust the water temperature as compared to changing the gas concentration, gas concentrations were randomized within temperature settings, i.e., the temperature was selected first, and then all gas concentrations were tested at that temperature before moving on to the next temperature. Once the actual temperature reached the set temperature, as indicated by a thermocouple in the water bath, the program triggered the relay switch for the first calibration gas. The program simultaneously began logging the voltage output and temperature from the oxygen sensors. The program stored the measurements from each oxygen sensor in individual CSV files. The gas flow through the system was maintained until the sensor outputs were at equilibrium, defined as less than $2 \%$ change in the oxygen sensor voltage output over a period of $5 \mathrm{~min}$. The program then switched to the next calibration gas and repeated this process until all five calibration gases were measured. The water bath temperature was then set to the next desired value in the random order specified. The process was repeated until all combinations of oxygen concentration and temperature were measured.

\section{Data Processing}

Every calibration run for a particular oxygen and temperature setting resulted in a unique time-based response, which was the combination of the time required for the calibration gas to purge the system and the sensor response time (fig. 2). 


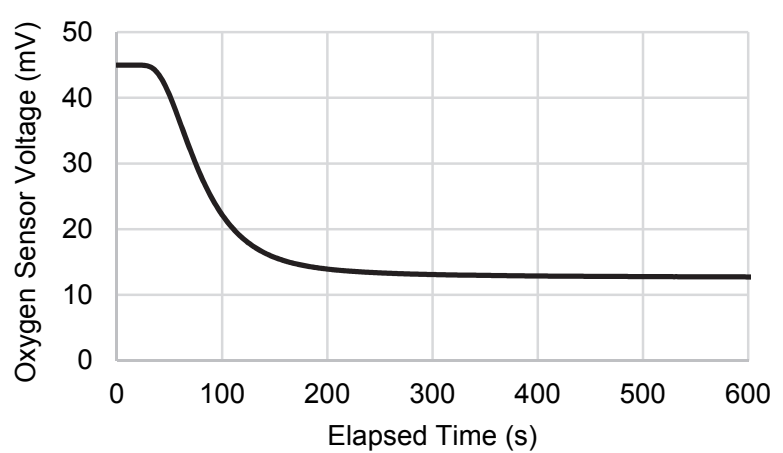

Figure 2. Example of uncalibrated oxygen sensor response from ambient to $5 \% \mathrm{O}_{2}$ at $10^{\circ} \mathrm{C}$.

Purge time was not independently quantified, and the sensor response time was specified to be $60 \mathrm{~s}$ by the manufacturer. Preliminary testing revealed that the response time required for the oxygen sensor voltage output to reach equilibrium was typically greater than $120 \mathrm{~s}$ when using this calibration method.

A MATLAB (R2013b, The Mathworks, Natick, Mass.) program was written to determine the steady-state values of the sensors from each response curve and compile them in a single array for each sensor. The Curve Fitting App in MATLAB was used to create a calibration equation that calculated oxygen percentage as a function of the oxygen sensor output voltage and temperature signals. First-, second-, and third-degree polynomial fits were used to model the calibration data from each sensor and then applied to validation data to test the models. Calibration gas oxygen concentration and temperature supplied to the oxygen sensors were treated as independent variables. Oxygen sensor voltage and temperature output signals were treated as dependent variables during regression. The regression equations were inverted to result in polynomial equations with two input parameters: the voltage and temperature output signals from the oxygen sensor. Root mean squared error (RMSE) and a 95\% PI were calculated between each polynomial equation and the validation data.

\section{Oxygen Profile Measurement}

To ensure viability in composting conditions, three SO120 oxygen sensors were calibrated using the previously described method and mounted into a probe that fixed the sensors vertically at intervals of $10.8 \mathrm{~cm}$ (4.25 in.). Each sensor was fitted with a diffusion chamber to prevent compost debris from plugging the sensor orifice. The assembly formed a prototype oxygen probe with sensors placed approximately 11,22 , and $33 \mathrm{~cm}$ below the compost surface (fig. 3).

The prototype oxygen probe was evaluated under controlled conditions. A $380 \mathrm{~L}$ container was filled with compost removed from a CBP barn at Harvest Home Dairy in Crestwood, Kentucky. The compost had an initial moisture content of approximately 68\% (mass basis). The container of compost was placed inside an environmental chamber set at $20^{\circ} \mathrm{C}$ and $35 \%$ relative humidity. The compost was mixed and allowed to rest for $24 \mathrm{~h}$ before mixing again. The prototype $\mathrm{O}_{2}$ probe was then inserted, and data were recorded for

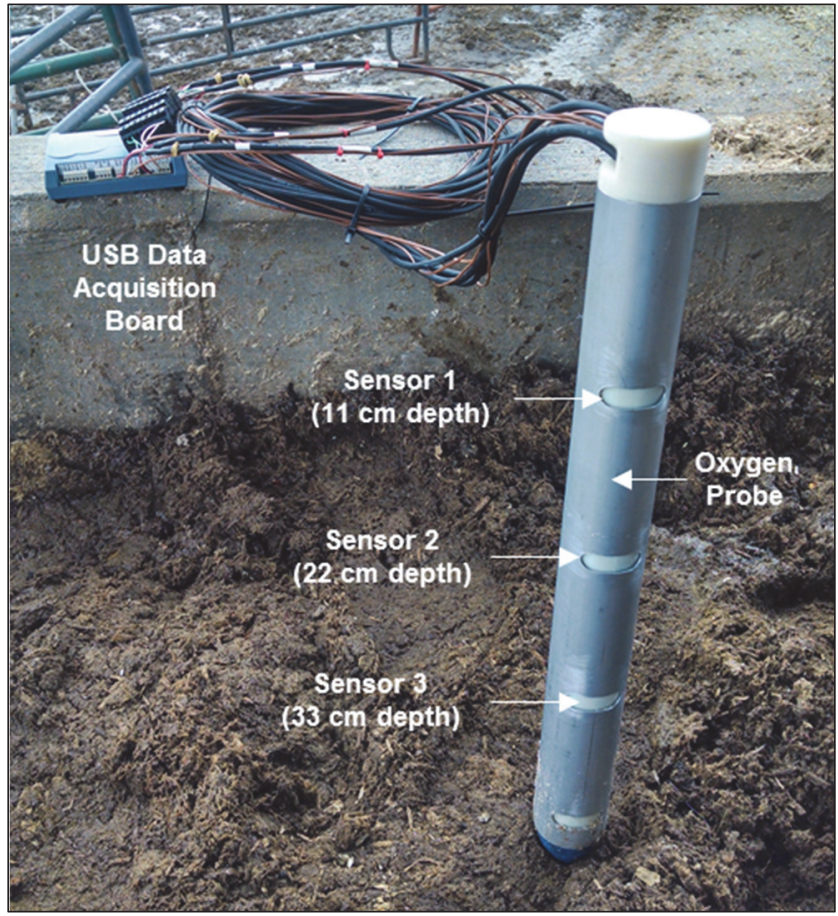

Figure 3. Prototype oxygen probe and USB data acquisition system.

$24 \mathrm{~h}$. This experimental setup did not constrain all boundary conditions in the same manner as would be expected in the field; however, it was assumed that a large enough container would be representative of the compost-air boundary layer to produce a gradient of oxygen within the compost.

\section{RESULTS AND DISCUSSION}

\section{SYSTEM PERFoRMANCE}

The calibration process took between 8 and $13 \mathrm{~h}$ per full cycle depending on the randomized order of the temperatures. $600 \mathrm{~L}$ ( $120 \mathrm{~L}$ per concentration) of calibration gas was used per trial. Three trials were averaged to create the calibration model, resulting in a total time to complete a calibration of approximately $32 \mathrm{~h}$ and a total of $1800 \mathrm{~L}$ of calibration gas used. The number of sensors that could be calibrated simultaneously was limited only by the size of the temperature-controlled water bath and the number of analog input ports on the DAQ board. Three sensors were simultaneously calibrated during this study.

\section{Calibration Results}

The calibration program was executed three times, recording 90 total response curves from each sensor. The results in figure 4 show that as the oxygen concentration and temperature of the measured gas increased, the oxygen sensor exhibited a non-linear response. A reduction in voltage was present as temperature increased for all oxygen concentrations tested other than $0 \% \mathrm{O}_{2}$. Both the magnitude of the reduction attributed to temperature and the variability between replications tended to increase as oxygen concentration increased. The cause of this phenomenon was not investigated, but its presence indicated the need for a higher-degree calibration method. 


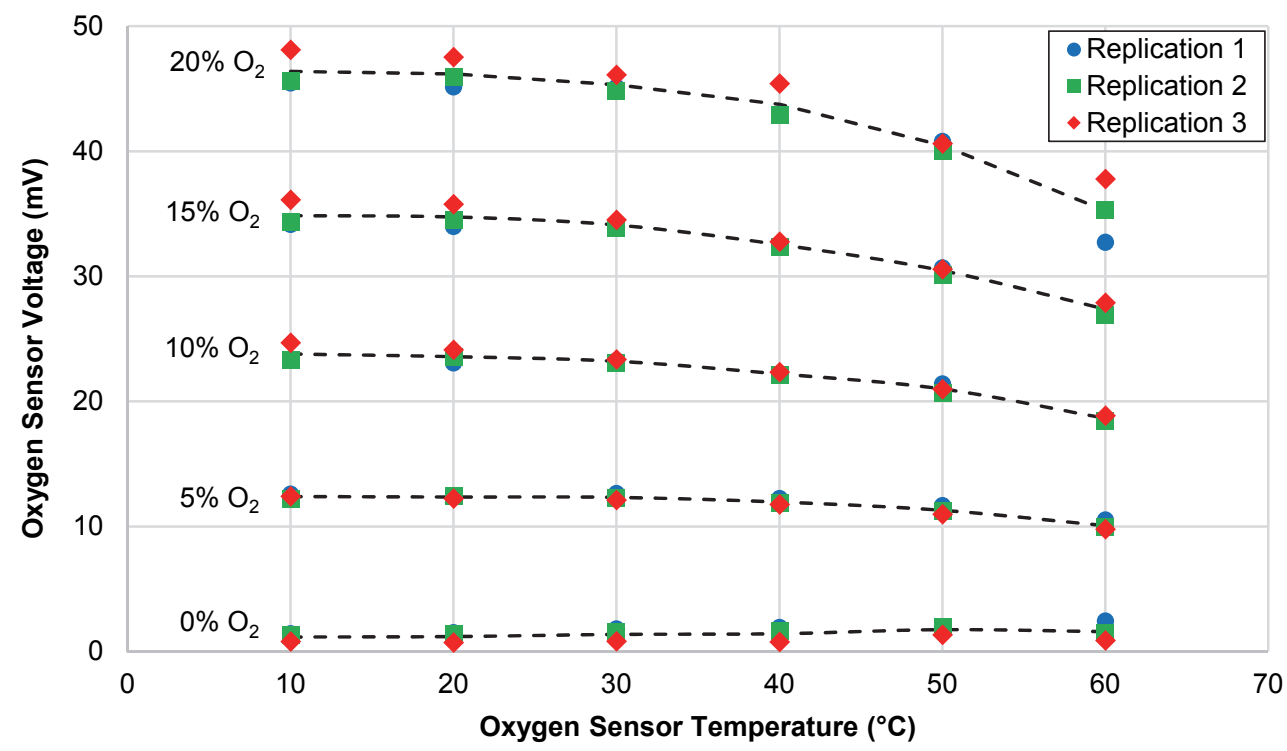

Figure 4. Example of oxygen sensor voltage response from three calibration replications of a single oxygen sensor.

Table 1 provides the resulting RMSE values for each sensor with respect to the degree of the second-degree model. The third-degree model exhibited the lowest RMSEs; however, the results of further analysis shown in table 2 suggested that several of the parameters in the third-degree model for one of the sensors were not significant (the confidence interval crossed zero for $p_{01}, p_{02}$, and $p_{03}$ ). This indicated that the second-degree model was a better choice and still substantially reduced RMSE as compared to the firstdegree model. Table 2 also demonstrates the variability in regression between sensors, regardless of the degree model used.

The form of the second-degree model is shown in equation 1:

$$
\% \mathrm{O}_{2}(x, y)=p_{00}+p_{10} x+p_{01} y+p_{11} x y+p_{02} y^{2}
$$

Table 1. RMSE values $\left(\% \mathrm{O}_{2 .}\right)$.

\begin{tabular}{cccc}
\hline $\begin{array}{c}\text { Polynomial } \\
\text { Degree }\end{array}$ & Sensor 1 & Sensor 2 & Sensor 3 \\
\hline 1 & 0.816 & 0.8825 & 0.9002 \\
2 & 0.3771 & 0.4726 & 0.406 \\
3 & 0.2539 & 0.3878 & 0.2365 \\
\hline
\end{tabular}

where

$x=\mathrm{O}_{2}$ sensor voltage $(\mathrm{V})$

$y=$ temperature $\left({ }^{\circ} \mathrm{C}\right)$

$p_{00}, p_{10}, p_{01}, p_{11}$, and $p_{02}=$ calibration coefficients.

A 95\% prediction interval (PI) was approximated for each sensor using RMSE, as shown in equation 2 :

$$
95 \% \text { PI }= \pm 2 \text { RMSE }
$$

The prediction intervals for the second-degree model were $\pm 0.75 \%, \pm 0.95 \%$, and $\pm 0.81 \% \mathrm{O}_{2}$ for sensors 1,2 , and 3 , respectively. If the manufacturer-recommended two-point calibration method had been used, then the prediction intervals would have been $\pm 1.94 \%, \pm 2.18 \%$, and $2.56 \% \mathrm{O}_{2}$, respectively. This result further validates the decision to include a more rigorous calibration process.

\section{OXygen Profile Results}

Figure 5 shows the prototype oxygen probe output response after insertion into a container of compost under controlled conditions. Initial oxygen concentration for all sensors was near $21 \% \mathrm{O}_{2}$ owing to the ambient air inside the

Table 2. Calibration equation coefficients with $95 \%$ confidence intervals.

\begin{tabular}{ccccc}
\hline $\begin{array}{c}\text { Polynomial } \\
\text { Degree }\end{array}$ & $\begin{array}{c}\text { Coefficients } \\
(95 \% \mathrm{CI})\end{array}$ & Sensor 1 & Sensor 2 & Sensor 3 \\
\hline \multirow{3}{*}{1} & $p_{00}$ & $-3.532(-4.178,-2.886)$ & $-3.423(-4.12,-2.726)$ & $-3.727(-4.442,-3.012)$ \\
\cline { 2 - 5 } & $p_{10}$ & $462.2(451,473.5)$ & $323.1(314.6,331.7)$ & $430(418.5,441.6)$ \\
& $p_{01}$ & $0.02723(0.02162,0.03283)$ & $0.02727(0.02121,0.03333)$ & $0.03283(0.02663,0.03903)$ \\
\hline & $p_{00}$ & $3.621(2.665,4.577)$ & $3.61(2.414,4.805)$ & $4.208(3.174,5.243)$ \\
\cline { 2 - 5 } 2 & $p_{10}$ & $340.3(323.6,356.9)$ & $231.9(217.4,246.5)$ & $302.5(285.8,319.2)$ \\
& $p_{01}$ & $-0.1056(-0.1253,-0.0858)$ & $-0.1006(-0.1253,-0.07588)$ & $-0.1154(-0.1368,-0.09399)$ \\
\cline { 2 - 5 } & $p_{11}$ & $1.374(1.198,1.551)$ & $1.031(0.8759,1.186)$ & $1.448(1.27,1.626)$ \\
\hline & $p_{02}$ & $0.000535(0.0004365,0.0006336)$ & $0.0004988(0.0003753,0.0006223)$ & $0.000602(0.0004955,0.0007085)$ \\
\hline & $p_{00}$ & $-2.861(-5.137,-0.5855)$ & $-1.811(-5.281,1.659)$ & $-4.027(-6.154,-1.899)$ \\
& $p_{10}$ & $515.5(479.2,551.7)$ & $352.6(314.2,391.1)$ & $493.4(461.9,524.8)$ \\
& $p_{01}$ & $0.07813(0.001698,0.1546)$ & $0.04572(-0.0709,0.1623)$ & $0.1251(0.05353,0.1966)$ \\
& $p_{11}$ & $-2.832(-3.668,-1.997)$ & $-1.871(-2.759,-0.9838)$ & $-3.148(-3.875,-2.421)$ \\
\hline & $p_{02}$ & $-0.0009479(-0.001763,-0.0001328)$ & $-0.0005767(-0.001821,0.0006673)$ & $-0.001441(-0.002203,-0.0006781)$ \\
\hline & $p_{12}$ & $0.02267(0.01821,0.02712)$ & $0.01565(0.01092,0.02039)$ & $0.02486(0.02097,0.02875)$ \\
& $p_{03}$ & $3.371 \mathrm{e}-06(5.776 \mathrm{e}-07,6.165 \mathrm{e}-06)$ & $1.974 \mathrm{e}-06(-2.291 \mathrm{e}-06,6.238 \mathrm{e}-06)$ & $5.088 \mathrm{e}-06(2.479 \mathrm{e}-06,7.697 \mathrm{e}-06)$ \\
\hline
\end{tabular}




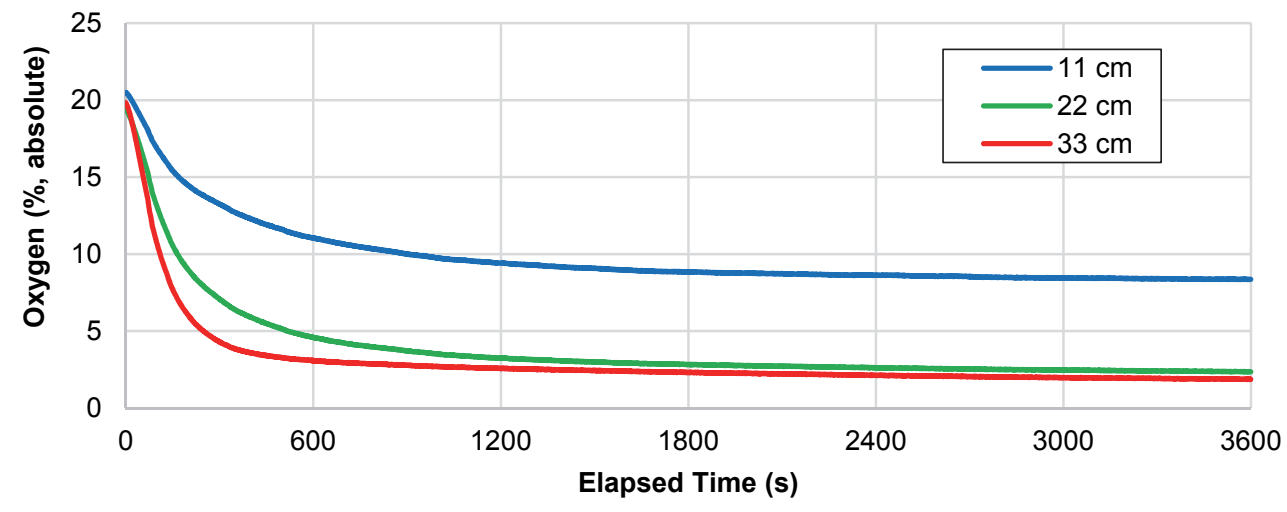

Figure 5. Prototype oxygen probe response versus time for three depths in compost at $1 \mathrm{~h}$ after insertion.

diffusion chambers and followed an exponential decay as diffusion occurred. The oxygen concentrations at $1 \mathrm{~h}$ were $8.3 \%, 2.4 \%$, and $1.9 \%$ for the 11,22 , and $33 \mathrm{~cm}$ depths, respectively. The oxygen concentrations at $24 \mathrm{~h}$ were $6.6 \%$, $1.0 \%$, and $1.0 \%$ for the 11,22 , and $33 \mathrm{~cm}$ depths, respectively. The temperature of the compost gradually increased from approximately $20^{\circ} \mathrm{C}$ to $43^{\circ} \mathrm{C}$ over the $24 \mathrm{~h}$ period, which indicated that the material was composting. The individual sensors were inspected and tested in ambient conditions after removal from the compost to ensure that moisture had not condensed inside the sensors. These results demonstrate the prototype oxygen probe's ability to measure variations in oxygen with depth.

\section{CONCLUSIONS}

An automated method for calibrating electrochemical oxygen sensors was developed. The calibration method was capable of recording sensor response at an array of temperatures and oxygen concentrations expected in composting conditions $\left(0 \%\right.$ to $20 \% \mathrm{O}_{2}$ and $10^{\circ} \mathrm{C}$ to $\left.60^{\circ} \mathrm{C}\right)$. The system removed the need for an operator to manually control gas concentration and temperature and the need to monitor system status while waiting for equilibrium. The system also provided the randomization needed when selecting calibration points to minimize bias due to external factors. Future work should include more precise control of the calibration gas humidity and additional sensors to ensure that the gas is saturated with moisture.

The prediction intervals were calculated using the manufacturer's two-point calibration and a second-degree polynomial model. The number of points sampled and the use of a second-degree model resulted in smaller prediction intervals, which is expected to result in the detection of smaller in-field differences in oxygen concentration levels.

Preliminary testing in a composting environment showed that the sensors were effective at measuring differences in oxygen concentration at varying depths. It is anticipated that this sensing method may reveal differences in tillage effectiveness by directly measuring changes in the oxygen concentration before and after different tillage treatments.

\section{ACKNOWLEDGEMENTS}

This is Publication No. 17-05-040 of the Kentucky Agricultural Experiment Station and is published with the approval of the Director.

\section{REFERENCES}

Agnew, J. M., \& Leonard, J. J. (2003). The physical properties of compost. Compost Sci. Util., 11(3), 238-264. https://doi.org/10.1080/1065657X.2003.10702132

Bernal, M. P., Alburquerque, J. A., \& Moral, R. (2009). Composting of animal manures and chemical criteria for compost maturity assessment: A review. Bioresour. Tech., 100(22), 5444-5453. https://doi.org/10.1016/j.biortech.2008.11.027

Black, R. A., Taraba, J. L., Day, G. B., Damasceno, F. A., \& Bewley, J. M. (2013). Compost bedded pack dairy barn management, performance, and producer satisfaction. J. Dairy Sci., 96(12), 8060-8074. https://doi.org/10.3168/jds.2013-6778

Gea, T., Barrena, R., Artola, A., \& Sánchez, A. (2004). Monitoring the biological activity of the composting process: Oxygen uptake rate (OUR), respirometric index (RI), and respiratory quotient (RQ). Biotech. Bioeng., 88(4), 520-527. https://doi.org/10.1002/bit.20281

Guo, R., Li, G., Jiang, T., Schuchardt, F., Chen, T., Zhao, Y., \& Shen, Y. (2012). Effect of aeration rate, $\mathrm{C} / \mathrm{N}$ ratio, and moisture content on the stability and maturity of compost. Bioresour. Tech., 112, 171-178. https://doi.org/10.1016/j.biortech.2012.02.099

He, Y., Inamori, Y., Mizuochi, M., Kong, H., Iwami, N., \& Sun, T. (2000). Measurements of $\mathrm{N}_{2} \mathrm{O}$ and $\mathrm{CH}_{4}$ from the aerated composting of food waste. Sci. Total Environ., 254(1), 65-74. https://doi.org/10.1016/S0048-9697(00)00439-3

Hogan, J. A., Miller, F. C., \& Finstein, M. S. (1989). Physical modeling of the composting ecosystem. Appl. Environ. Microbiol., 55(5), 1082-1092.

Rynk, R., van de Kamp, M., Willson, G. B., Singley, M. E., Richard, T. L., Kolega, J. J., ... Brinton, W. F. (1992). On-farm composting handbook. NRAES-54. Ithaca, NY: Northeast Regional Agricultural Engineering Service. Retrieved from https://campus.extension.org/pluginfile.php/48384/course/section /7167/NRAES\%20FarmCompost\%20manual\%201992.pdf

USDA. (2007). Dairy 2007: Part IV. Reference of dairy cattle health and management practices in the United States. Fort Collins, CO: USDA-APHIS Center for Epidemiology and Animal Health. Retrieved from https://www.aphis.usda.gov/animal_health/nahms/dairy/downloa ds/dairy07/Dairy07_dr_PartIV.pdf 